\title{
Designing excuses for interaction to facilitate social curiosity
}

\author{
Mads Hobye \\ IMT, RUC, DK \\ www.hobye.dk \\ mads@hobye.dk
}

\author{
Nicolas Padfield \\ Fablab RUC, DK \\ fablab.ruc.dk \\ nicolas@padfield.dk
}

\author{
Jonas Löwgren \\ Linköping University, SE \\ jonas.lowgren.info \\ jonas.lowgren@liu.se
}

\begin{abstract}
We present potentials of creating excuses as a central metaphor for a design strategy - excuses to interact (a "ticket to talk") as a way to facilitate social interactions among participants. Interaction design has, in its third wave, moved towards the more abstract experiential potentials of designing for embodied playful interactions, but much is needed to understand the dynamics of social interaction and how one can design for social curiosity. With this perspective we move beyond tangible curiosity, attempting to break restraint, timidity and shyness - using touch to design for bending social norms. We build the concept of creating excuses to interact based on three large experiments with interactive art installations presented in a festival context. We attempt to convert the particular design cases into general understandings of a set of potential design strategies, with the intention to create generative design knowledge. Extremely simple technical rules can be designed with the sole purpose of breaking down normal social restraints and provoking interesting social interaction.
\end{abstract}

\section{CCS CONCEPTS}

- Human-centered computing $\rightarrow$ Interaction design $\rightarrow$ Interaction design theory, concepts and paradigms.

\section{KEYWORDS}

Social curiosity, Open ended play, Interactive art, Interaction design.

\section{ACM Reference format:}

Mads Hobye, Nicolas Padfield and Jonas Löwgren. 2018. Designing excuses for interaction to facilitate social curiosity. In Proceedings of FDG'18, Malmö, Sweden , August 7-10, 2018, 6 pages.

DOI: $10.1145 / 3235765.3235828$

Permission to make digital or hard copies of part or all of this work for personal or classroom use is granted without fee provided that copies are not made or distributed for profit or commercial advantage and that copies bear this notice and the full citation on the first page. Copyrights for third-party components of this work must be honored. For all other uses, contact the Owner/Author.

FDG18, August 7-10, 2018, Malmö, Sweden

(C) 2018 Copyright is held by the owner/author(s). ACM ISBN 978-1-4503-6571-0/18/08. https://doi.org/10.1145/3235765.3235828

\section{INTRODUCTION}

"Come here and hold hands with me!" a girl would call out to a random passerby, deep in the mud of Roskilde Festival. Roskilde Festival is mainland northern Europe's largest popular music festival, with approximately 100.000 participants. People would look at her in surprise, sometimes disbelief. The ensuing conversation would go along the lines of "why?" "we can make fire" "are you crazy?" "no, no, if we connect these two poles with our bodies, we get fire!" "I won't get an electrical shock?". Prompting these recurring impromptu discussions on novel human-machine interaction was the interactive installation Medusae Nilfisk, consisting of three large fire cannons 6 meters above the ground. It quickly became a recurring theme to see participants running around, trying to find people to hold hands with. Touch became something more than the relationship between user and interface - by requiring interpersonal touch, touch became social.

Interaction design has long focused on designing the interaction between the user and the technology (interface). In this work we focus on designing artefacts and interfaces that focus on fostering interpersonal social interaction by participants, around the interface. When we in the following refer to "touch", we mean interpersonal touch, often between strangers. We use cases as examples of how interfaces can be designed to foster performative interpersonal social interactions. The cases are explorative designs empirically studied, created by the authors, both alone and as members of the interactive collaborative art group illutron.

\subsection{Excuse for social curiosity}

Designing objects of curiosity has been modelled by Tieben et al. [17] as a circular modus where an encounter creates novelty, uncertainty or conflict to provoke the need for exploration. Essentially exploring in the sense of "what's that?". Through the object's novelty the user is invited to create new meanings and understandings. This lasts until "unknown" has been resolved and a new novel encounter needs to appear for the circle to start over. This is primarily a dynamic between the object and the user who holds the curiosity, but does not give a foundation for reflection on how to design for social curiosity. Similarly Gaver's [8] notion of ambiguity and his proposal of designing for Homo Ludens [6], 
is a move away from transparent interfaces towards exploring possible ways of creating new experiences and relations in interactive designs. As Gaver phrases Homo Ludens: viewing humans as "characterised not just by our thinking or achievements, but by our playfulness: our curiosity, our love of diversion, our explorations, inventions and wonder."[6] We want to argue for the importance of designing for ambiguity and Homo Ludens from the perspective of social dynamics. By social dynamics we mean situated as in Dourish [4], but focusing not merely on interaction with the artifact and the context it is placed in, but also interaction between subjects, around the artifact. It becomes a way of intentionally exploiting the added ambiguity inherent in interacting with another person, a stranger. While the cases are intentionally situated in unusually playful contexts where social mores are already relaxed, and socially curious interactions, chance encounters, engaging with strangers are more normal, we try to extrapolate for more generalizable designs.

Moving from curiosity of objects to social curiosity introduces new challenges. People want to feel connected with others and therefore innately want to seek out interactions [13]. However, social awareness is a dominant inhibitor for participants to engaging in social curiosity with other participants. Situated spaces hold normative connotation of interaction [9]. It is our impression that even the festival-like contexts in which our installations have been tried out in do not necessarily break down this inhibitor. A performative awareness [14] can quickly arise and overwhelm the individual participant, causing passivity. Further, Silvia [15] introduces two kinds of properties for curious emotions. First, similar to Tieben, is "an evaluation of an event's novelty-complexity". Second is an evaluation of an event's comprehensibility. From the perspective of social curiosity this means that for social curiosity to flourish there should be a potential for novel and chance encounter, while staying within a comprehensible comfort zone. Through 10 years of experiments with facilitating social interaction through interactive installations we have observed "excuses to interact" as a recurring property of facilitating social curiosity where comprehensible-novelty is present. Designing excuses for interaction has the ability to create a dynamic around the installations in which the participants dare approach one another. We go as far as to postulate that people seek an excuse for social interaction without explicit justification. By excuse to interact we mean a design that in a specific context has the ability to facilitate opportunities or excuses to interact between strangers. It is a way to "resort to alibis, motivational accounts that deflect negative inference from their play behavior to their character." [3]

\subsection{Research through explorative design}

Our intention is not to make a solid definition of social curiosity as a contribution to fundamental knowledge within psychology, anthropology, sociology etc. or, but merely to highlight a set of design strategies or tactics within the umbrella of creating excuses, for other designers to use within a wide range of design fields (HCI, Interaction Design, Game Design etc.). Our premise for our knowledge contribution is that the research community needs exemplified design research. This seemingly simple postulation has a few consequences, though, having to do with the fact that design research operates on principles of its own. First, in design research, the artifacts are knowledge contributions in themselves, rather than a mere apparatus for user testing. An endless string of design examples is at the core of how design research should operate, and the role of theory should be to annotate those examples rather than replace them. Secondly, design research is not about answering precise research questions or falsifying hypotheses through controlled experiments. Rather, its ultimate goal is to explore potentials and assess possibilities for progressive inquiry where design practice is the main vehicle.

Broadly speaking, our research method is characterized as Research Through Explorative Design [11], drawing heavily on the emerging tradition of Research Through Design within the CHI community [18] but emphasizing more strongly the explorative nature of design practice as part of knowledge production: experiments in the wild, intuitively guided forays into uncharted design spaces. This paper presents three design experiments in the general area of designing for social play through interpersonal touch, and then develops a systematic reflection where insights from the experiments are related to the research questions and to pertinent analytical concepts from the literature. It is thus similar in kind to what Gaver and Bowers [1, $5,7,14]$ call an annotated portfolio.

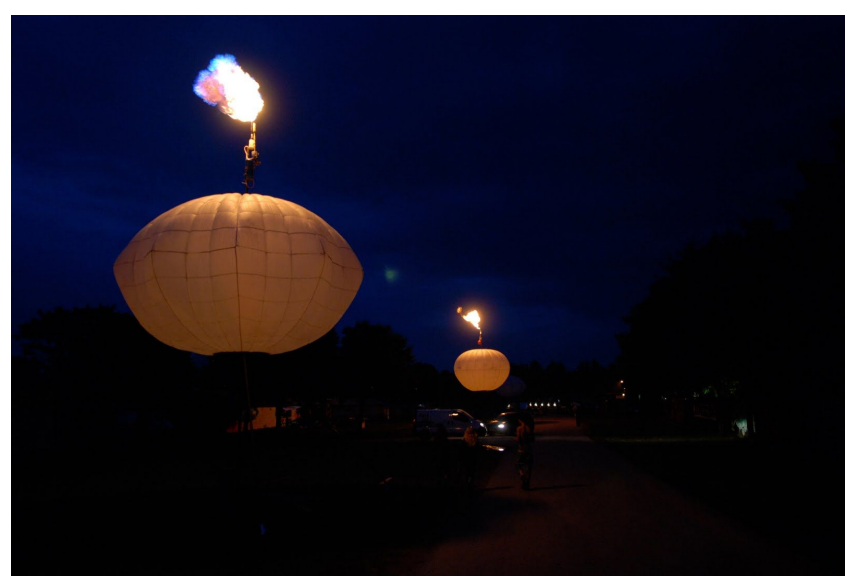

Figure 1: Medusae Nilfisk installation explosion 


\section{BRIEF INTRODUCTION OF CASES}

The following section offers brief descriptions of three selected interactive installations. We will delve deeper into the specific cases in context and how they relate to excuses for social curiosity.

\subsection{Case 1: The Singing Plant}

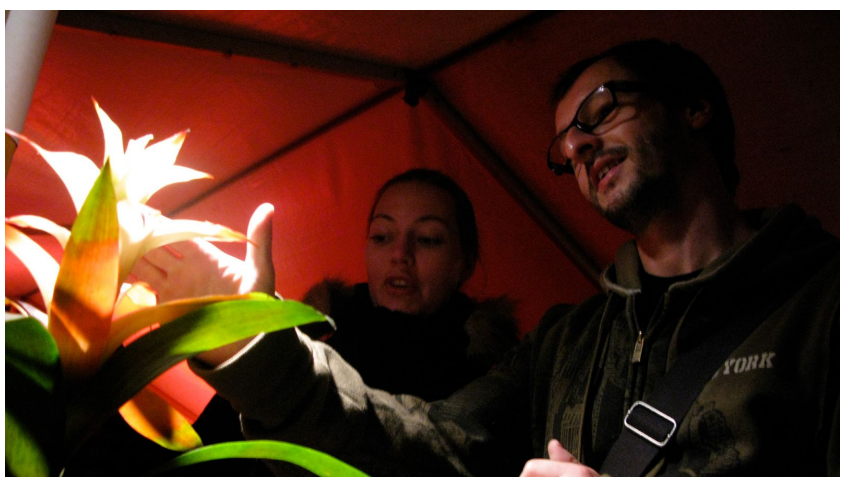

Figure 2: Participants exploring the plant through touch

The singing plant [10] is an interactive sound and light installation using a living green house plant as the sole interactive interface element. It is based upon one of the first electronic musical instruments - the Theremin, named after its inventor, the Russian professor Léon Theremin. Normally a Theremin antenna is metal but in the Singing Plant, a plant is used as the antenna, acting as a touch and proximity sensor which controls pitch and volume. In the concrete installation, the sound was modulated through several filters to give a richer and more variable soundscape.

\subsection{Case 2: Medusae Nilfisk}

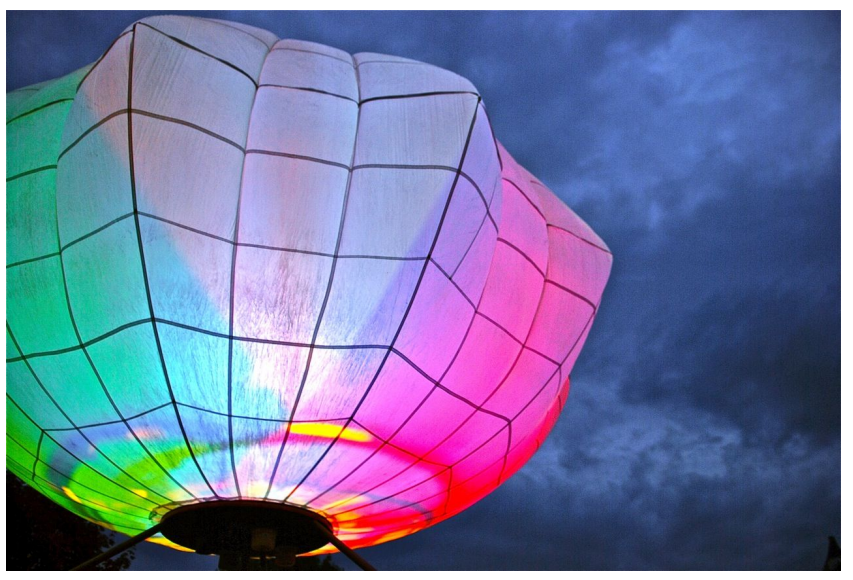

Figure 3:Medusae Nilfisk is a large interactive light and fire installation.

The installation consisted [10] of three floating inflated spheres, large ovaloids sewn from used military parachutes, kept inflated with antique vacuum cleaners. Within each ovaloid there were four large incandescent lamps, one white and three in the primary colours red, green and blue. These cycled slowly through the colours of the rainbow. On top of each sculpture was a propane driven fire cannon. The audience could interact with the installation by creating an electrical connection between two poles. The poles were placed too far from each other for one person to accomplish this alone, requiring at least three people cooperating. Connecting the poles started an animated sequence of light, culminating with the flame effects on all three lamps being fired.

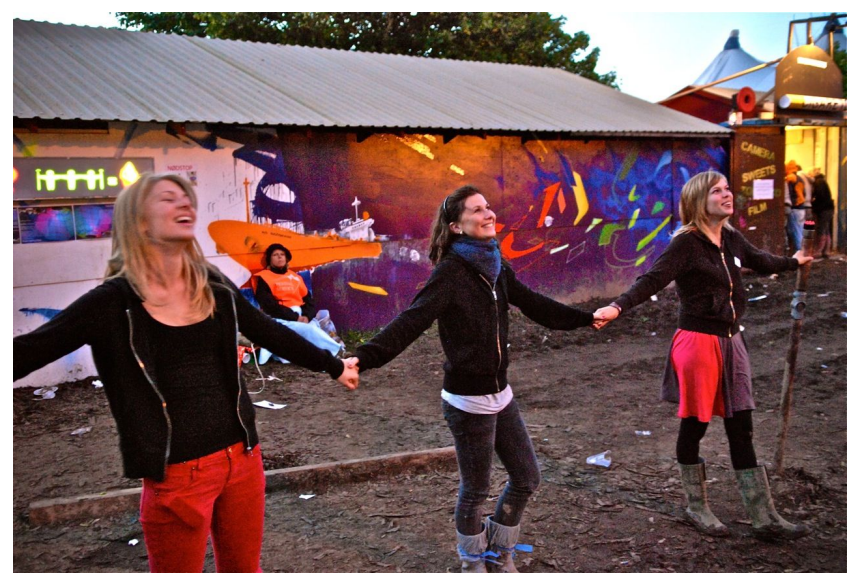

Figure 4: Participants holding hands to trigger the fire/light installation.

\subsection{Case 3: Mediated Body}

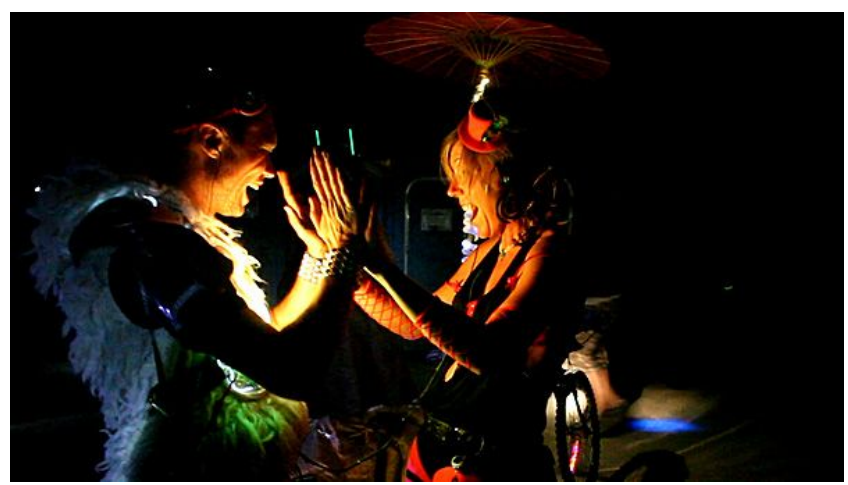

Figure 5: Participant and performer exploring the intimacy of interpersonal touch

The suit [10] consists of a breastplate containing a coil of RGB (red-green-blue) LED (light emitting diodes), two pairs of specially modified headphones and a fanny pack containing an Arduino, electronics and battery pack. Mediated Body is worn by a performer wishing to engage in social interaction and play. The headphones include a conductive pad touching the participant's ear; this constitutes the electric circuit required to measure the 
impending skin to skin contact. When the participant and performer touch each others' bare skin, the suit reacts both auditively and visually. Both people hear the same complex sound pattern through their headphones. The lights on the suit also change, offering immediate visual feedback on the tactile input.

\section{Strategies for creating excuses to interact}

As the three cases show, our work is essentially an exploration of intimate organic and interpersonal curiosity, and its consequences for social interaction. We will argue that there are significant connections between the detailed design of the interfaces and the complex social interactions emerging around them, and our argument is structured as follows:

\subsection{Creating excuses for exploration}

We propose using interface design which is novel and has internal complexity to create excuses for exploration.

Different physical interfaces can foster different social dynamics. Redström [12] points out that microprocessors create a discrepancy between physical appearance and the interaction with it. One can say that the "gears and levers" with a direct coupling between function and representation have been replaced with code in chips reacting to hidden (or at least tiny) sensors. Although this adds new challenges from a usability point of view, it also facilitates exploitation of new social meanings. In our cases we have experimented with different input and output designs; based on novel interfaces like plants, humans (binary - hold hand or not), humans (analogue - stroking interface) and metal poles as input sensors.

The novelty of the singing plant enabled new meaning and sparked ongoing discussions about its aura, feelings, supernatural powers, its living nature etc. The poles gently pushed social boundaries - holding hands with strangers - using the common goal of seeing the fire cannons go off.

Mediated Body made a novel and explorable connection between interpersonal touch and sound, serving both as an excuse to touch, and fostering an honest curiosity and need for understanding the relationship between touch and sound. Furthermore, the interaction is embodied [4] and depends heavily on context. For example, there was a vast difference when we exhibited the plant in the Botanical gardens vs. Roskilde music festival. The latter made for a more aggressive and playful interaction than the more polite and careful interaction in the Botanical gardens; a garden with a museum-like setting.

The nuances of the interaction and the size of the possibility space to explore makes for explorative and sustained interaction. An example is the poles you connect to ignite fire. Here there was a minimum number of people required to make the connection but no maximum number. This was enough to make participants wonder how how long a chain they could make. Since the connection is not stronger than the weakest link it sometimes took multiple attempts to get everyone to hold hands at the same time. A more complex example is the "aura" in Mediated Body. Here the balance of touching and not touching proved to be enticing to explore.

\subsection{Create excuses for social intimacy}

Our three designs encourage participants to become explorative and even playful through the ambiguous interfaces and their internal complexity. Playful in the sense of: "Playful would be that which plays with the frames of play."[16] Here it is not only play, but also play with social norms; a negotiation of boundaries between strangers in the process of getting to know each other. By introducing interpersonal touch installations we have managed to move from play with the artifact in a social setting to socially playing with the setting, sometimes to the point where the artifact itself becomes invisible or secondary.

Interpersonal touch is more socially direct than e.g. touching the singing plant. Touching another person is a direct social act directed towards that person. It demands some sort of social follow-through or pre-negotiation. We have the advantage that touching a stranger is always ambiguous; the experience is novel and reactions unknown and somewhat exciting, and it is difficult to not read a lot of expectations and intentionality into the the object (the other person). This may be assisted by the novelty of the interface form - it is an open question whether this interface form will continue to have this role if the participants have experienced something similar several times - or perhaps the exploration of another person's personal sphere will remain novel due to social norms of the surrounding society.

Playing with social frames often involves or even exploits ambiguity. Gaver proposes that ambiguity can encourage closer engagement and social relations with the system.

"We argue ... that [ambiguity] is a resource for design that can be used to encourage close personal engagement with systems." [8]

We take this a stage further and propose that ambiguity in the system can be a resource and useful tactic not only for encouraging users to relate to the system, but for creating ambiguous social dynamics around the system. We propose ambiguity as a tool for expanding negotiation of social norms via the system.

Gaver [8] specifies different kinds of ambiguity (information, context, relationship), but focuses almost exclusively on the relationship to the system, and to some extent on the conversations about it. There is not much about the social 
relationships around the system. As our work concentrates on social play through interpersonal touch, we need to add the category of social ambiguity. To elaborate, we return to the design experiments and show how social ambiguity manifests itself in each of them.

In Medusae Nilfisk the ambiguity is in drawing in, interacting with and touching other participants for a shared goal. At first glance, Medusae Nilfisk would appear to be a simple reward-based interface: Make a chain of touch and you get your reward in the form of pyrotechnic release. But the dialogue around gathering people to make the chain turned out to be an ambiguous process involving constant exchange between the participants, and for many participants the process became at least as interesting as the reward. This means we must differentiate between initial motivation and primary interface characteristics. The motivation for starting was to make fire, but the actual experience was social as well as pyrotechnic.

Mediated Body has multiple layers of ambiguity - the interface itself, ambiguity in the social interaction with the performer and ambiguity relating to the contrast between the social insulation of the performer and participant from the audience.

There appear to be various possible tactics. There can be multiple layers of intent at the same time: exploration of the (designed) interaction and actual curiosity of touch (the side effect of the chosen interaction medium). We can use or abuse existing cultural norms to focus on social dynamics and push social norms.

Although the negotiation of social norms is done through 'innocent' play it still opens up a performative aspect. This raises participants' awareness of the space and their role in it; their performance. We will unfold this further in the following section.

\subsection{Create excuses for performative agency}

The social dynamics around the installations took on a life of their own: the ongoing negotiations around the poles in the Medusae Nilfisk installation; the circle formed around the performer with the Mediated Body; the banter about how one could hear the plant's 'aura' - all these were qualities we as designers only intuitively imagined parts of. We were not directors, but could observe how the participants turned into operators, performers and observers simultaneously [2]. Our work illustrates performative interaction in this general sense, but what is more, it pushes the envelope towards social play due to the qualities of the ambiguous interface and intimate touch interactions that were designed. We can observe people negotiate social boundaries and heighten their awareness of the social space. In essence, we focus on playfulness in the sense of playing with the frame of play, enabling participants to explore their own roles and understandings in negotiation with the people around them.
With the Singing Plant, Medusae Nilfisk and Electrolumen, we observed that participants, after an initial exploration, took on a performing, mediating role. We interpret this facilitating role as an excuse to socially engage with others, sometimes for the purpose of displaying prowess. Patterns that had emerged without our design or intervention were often perpetuated. This enabled even non-obvious interfaces to achieve a low threshold where participants learned from more experienced participants. If there were no participants with previous knowledge, we ourselves had to kick-start the process by playing with the installation. Mediated Body is the only installation with an actual performer present. Here the performer is a 'professional', a designed part of the system. This somewhat limits the realm of possible actions, as participants tend to more passively follow the lead of the performer.

\section{CONCLUSION}

To recapture the main arguments presented in this text, we argue that one can design interfaces and interaction for fostering complex social curiosity. Furthermore we argue for the agency of the designer in the sense that there are strong connections between the workings of the system, the interaction surface and in the end the social dynamics around it.

Putting focus on ambiguous design can be a resource for creating playful social dynamics. For us ambiguous computing is about embracing plurality, about embracing and using the fact that the meaning is mediated in collaboration with the participants to enhance social processes. By playing with social norms one has the possibility to create intriguing works. Organic touch and social ambiguity are two specific design treatments that are conducive to performative and captivating use experiences.

Designing for ambiguity allows for social curiosity in which the participants can use the interactive installations as excuses to socially interact with each other. What initially was a byproduct in the design, has become a central element of designing socially curious installations. There are many ways of designing for such excuses to interact. We have have pinpointed three dimensions that we propose as generative properties for interaction designers to consider. Creating some level of exploration and novelty enables conversations around meaning and norms. Touch based interaction design is an effective way to enable excuses for interest more related to social intimacy. If the participants can use the installations as an excuse to guide others, the installation provides performative agency for social curiosity. It enables the participants themselves to become guides; fostering situations where participants become performers in a social re-negotiation of norms and rules. Integrating a performer or guide into an installation has a tendency to limit the motivation for the 
participants taking on the role of performer, for themselves as well as for each other.

Similar to an integrated performer limiting the space for negotiation of norms and meaning among the participants, competition based game design can have the same effect. The inherent open ended ludic properties of the designs presented in this paper are key to understanding the potential of creating excuses for interaction. However, much actual game design is less about winning, but about similar playfully ludic interaction in which the participants are using the game itself as an excuse for social curiosity. Twister is a seminal example of such design. Many computer based games are more about the play experience itself than the outcome. What constitutes a game thus becomes a more broadly defined to include a more ludic focus.

\section{ACKNOWLEDGEMENTS}

\section{Singing Plant}

Mads Hobye, Nicolas Padfield, Schack Lindemann, Thomas Jørgensen, Thor Lentz and Åsmund Boye Kverneland.

\section{Medusae Nilfisk}

Bo Boye, Harald Viuff, Mads Hobye, Nicolas Padfield, Nikolaj Møbius, Schack Lindemann, Thomas Jørgensen and Vibeke Hansen.

\section{Mediated Body}

Bent Haugland, Mads Hobye, Nicolas Padfield, Nikolaj Møbius and Nynne Just Christoffersen.

Variations of the descriptions of the art cases occur in other of our articles.

\section{REFERENCES}

[1] Bowers, J. 2012. The logic of annotated portfolios: communicating the value of 'research through design'. Proceedings of the Designing Interactive Systems Conference (Jun. 2012), 68-77.

[2] Dalsgaard, P. and Hansen, L.K. 2008. Performing perception — staging aesthetics of interaction. ACM transactions on computer-human interaction: a publication of the Association for Computing Machinery. 15, 3 (2008), 1-33. DOI:https://doi.org/10.1145/1453152.1453156.

[3] Deterding, S. 2018. Alibis for Adult Play: A Goffmanian Account of Escaping Embarrassment in Adult Play. Games and culture. 13, 3 (May 2018), 260-279. DOI:https://doi.org/10.1177/1555412017721086.

[4] Dourish, P. 2004. Where the Action is: The Foundations of Embodied Interaction. MIT Press.

[5] Gaver, B. and Bowers, J. 2012. Annotated portfolios. Interactions. 19, 4 (Jul. 2012), 40-49. DOI:https://doi.org/10.1145/2212877.2212889.

[6] Gaver, W. 2009. Designing for Homo Ludens, Still. (Re)searching the Digital Bauhaus. J. Löwgren and L. Malmborg, eds. Springer. 163-178.

[7] Gaver, W. 2012. What should we expect from research through design? Proceedings of the SIGCHI Conference on Human Factors in Computing Systems (May 2012), 937-946.

[8] Gaver, W.W. et al. 2003. Ambiguity as a resource for design. Proceedings of the SIGCHI Conference on Human Factors in Computing Systems (Apr. 2003), 233-240.

[9] Goffman, E. 1966. Behavior in public places: Notes on the social organization of gatherings. Free Press.

[10] Hobye, M. et al. 2013. Designing social play through interpersonal touch: An annotated portfolio. (2013).

[11] Hobye, M. and Löwgren, J. 2011. Touching a stranger: Designing for engaging experience in embodied interaction. International Journal of Design. 5, 3 (2011), 31-48.

[12] Redström, J. 2008. Tangled interaction. ACM transactions on computer-human interaction: a publication of the Association for Computing Machinery. 15, 4 (2008), 1-17. DOI:https://doi.org/10.1145/1460355.1460358.

[13] Ryan, R.M. and Deci, E.L. 2000. Self-determination theory and the facilitation of intrinsic motivation, social development, and well-being. The American psychologist. 55, 1 (Jan. 2000), 68-78.

[14] Schechner, R. 2003. Performance theory. Routledge.

[15] Silvia, P.J. 2008. Interest-The Curious Emotion. Current directions in psychological science. 17, 1 (Feb. 2008), 57-60. DOI:https://doi.org/10.1111/j.1467-8721.2008.00548.x

[16] Sutton-Smith, B. 2001. The Ambiguity of Play. Harvard University Press.

[17] Tieben, R. et al. 2011. Curiosity and interaction: making people curious through interactive systems. Proceedings of the 25th BCS Conference on Human-Computer Interaction (Jul. 2011), 361-370.

[18] Zimmerman, J. et al. 2007. Research through design as a method for interaction design research in HCI. Proceedings of the SIGCHI Conference on Human Factors in Computing Systems (Apr. 2007), 493-502. 